\title{
A proximal activator of transcription in epithelial-mesenchymal transition
}

\author{
Christo D. Venkov, ${ }^{1}$ Andrew J. Link, ${ }^{2}$ Jennifer L. Jennings, ${ }^{2}$ David Plieth, ${ }^{1}$ Tsutomu Inoue, ${ }^{1}$ \\ Kojiro Nagai, ${ }^{1}$ Carol Xu, ${ }^{1}$ Yoana N. Dimitrova, ${ }^{3}$ Frank J. Rauscher III, ${ }^{4}$ and Eric G. Neilson ${ }^{1,5}$
}

\begin{abstract}
1Department of Medicine, ${ }^{2}$ Department of Microbiology and Immunology, and ${ }^{3}$ Department of Biochemistry, Vanderbilt University School of Medicine, Nashville, Tennessee, USA. ${ }^{4}$ Wistar Institute, Philadelphia, Pennsylvania, USA. ${ }^{5}$ Department of Cell and Developmental Biology, Vanderbilt University School of Medicine, Nashville, Tennessee, USA.
\end{abstract}

\begin{abstract}
Epithelial-mesenchymal transition (EMT) is an important mechanism for phenotypic conversion in normal development and disease states such as tissue fibrosis and metastasis. While this conversion of epithelia is under tight transcriptional control, few of the key transcriptional proteins are known. Fibroblasts produced by EMT express a gene encoding fibroblast-specific protein 1 (FSP1), which is regulated by a proximal cisacting promoter element called fibroblast transcription site-1 (FTS-1). In mass spectrometry, chromatin immunoprecipitation, and siRNA studies, we used FTS-1 as a unique probe for mediators of EMT and identified a complex of 2 proteins, CArG box-binding factor-A (CBF-A) and KRAB-associated protein 1 (KAP-1), that bind this site. Epithelial cells engineered to conditionally express recombinant $C B F-A(r C B F-A)$ activate the transcription of FSP1 and undergo EMT. The FTS-1 response element also exists in the promoters modulating a broader EMT transcriptome, including Twist, and Snail, as well as E-cadherin, $\beta$-catenin, ZO 1, vimentin, $\alpha 1(I)$ collagen, and $\alpha$-smooth muscle actin, and the induction of $r C B F-A$ appropriately alters their expression as well. We believe formation of the CBF-A/KAP-1/FTS-1 complex is sufficient for the induction of FSP1 and a novel proximal activator of EMT.
\end{abstract}

\section{Introduction}

The mechanisms governing molecular signals for epithelialmesenchymal transition (EMT) are increasingly more complex $(1,2)$. Fibrogenesis during wound healing or following organ inflammation depends on the formation and proliferation of new fibroblasts by EMT. We previously described a gene encoding fibroblast-specific protein 1 (FSP1) that activates in epithelia during EMT and is constitutively and selectively present in newly formed fibroblasts thereafter; FSP1, also known as S100A4 in the cancer literature, is an intracellular calcium-binding protein whose appearance is linked to EMT (3-7), tissue fibrosis $(4,8)$, pulmonary vascular disease (9), increased tumor cell motility and invasiveness (10), and metastatic tumor development (11-16). FSP1 helps epithelia transition to new morphology and motility based on its ability to influence levels of intracellular calcium and actin disassembly when transfected into cultured cells. The important role of FSP1 in EMT is underscored by findings that induction of EMT in vitro by epithelial growth factor (EGF) and TGF- $\beta$ is blocked by antisense oligomers against mRNA encoding FSP1 (6) and that levels of mRNA encoding E-cadherin are inversely correlated with FSP1 expression in invasive lines of squamous cell carcinoma (17).

The transcriptional control of EMT diversifies the lineage specification of epithelia during development (18), lineage com-

Nonstandard abbreviations used: CBF-A, CArG box-binding factor-A; ChIP, chromatin immunoprecipitation; $\mathrm{Ct}$, threshold cycle; EEF1A1, eukaryotic elongation factor $1 \alpha 1$; EGF, epithelial growth factor; EMT, epithelial-mesenchymal transition; FSP1, fibroblast-specific protein 1; FTS-1, fibroblast transcription site-1; HMGA2, high mobility group A2; KAP-1, KRAB-associated protein 1; LEF-1, lymphoid enhancing binding factor; $\mathrm{mIMCD}$, mouse inner medullary collecting duct; qRT-PCR, quantitative real-time PCR; $r C B F-A$, recombinant $C B F-A$; SRE, serum response factor; UUO, unilateral ureteral obstruction; YB-1, Y-box transcription factor.

Conflict of interest: The authors have declared that no conflict of interest exists. Citation for this article: J. Clin. Invest. 117:482-491 (2007). doi:10.1172/JCI29544. mitment of epithelia in tissue fibrosis (1), and the stimulation of tumor metastasis $(2,11,19)$. An increasing number of transcription factors appear to activate EMT in various settings, including Snail (20), Twist (11), high mobility group A2 (HMGA2) (21), Slug (16), and Ets-1 $(22,23)$. However, the set of transcription factors controlling EMT is far from complete.

In an earlier report using promoter deletion constructs for FSP1, we identified a novel cis-acting element in the FSP1 promoter called fibroblast transcription site-1 (FTS-1), which activates transfected reporters in fibroblasts and forms specific complexes in EMSAs with nuclear extracts (24). Using both EMSA and DNA affinity chromatography followed by mass spectrometry analysis (25), we identified 2 key transcriptional proteins in this complex, namely the CArG box-binding factor-A (CBF-A) (26) and the KRAB-associated protein 1 (KAP-1) (27). These proteins form a ternary complex with FTS-1 to engage the transcription of FSP1 and play a key functional role in forming fibroblasts by EMT.

\section{Results}

Purification of the FTS-1-binding complex. In our original report of FTS-1 (24), we used a 100-bp oligonucleotide from the proximal FSP1 promoter to identify the fibroblast-specific complex by EMSA. To minimize the background while ensuring specificity of binding to the 5-nucleotide FTS-1 motif, this time we used a 25-bp sequence containing the core pentanucleotide (TTGAT) with adjacent promoter sequences. Complexes identified by EMSA using both oligonucleotides and fibroblast nuclear extracts had a similar number and pattern of distribution when run in parallel (Figure 1A); differences in the relative mobility of the bands arose from the different lengths of the oligonucleotides. The 4 complexes were competed to varying degree by challenge with $20 \times$ molar excess unlabeled probe. The specificity of the complexes formed with the 25-bp FTS-1 oligonucleotide was further tested by competition analysis 

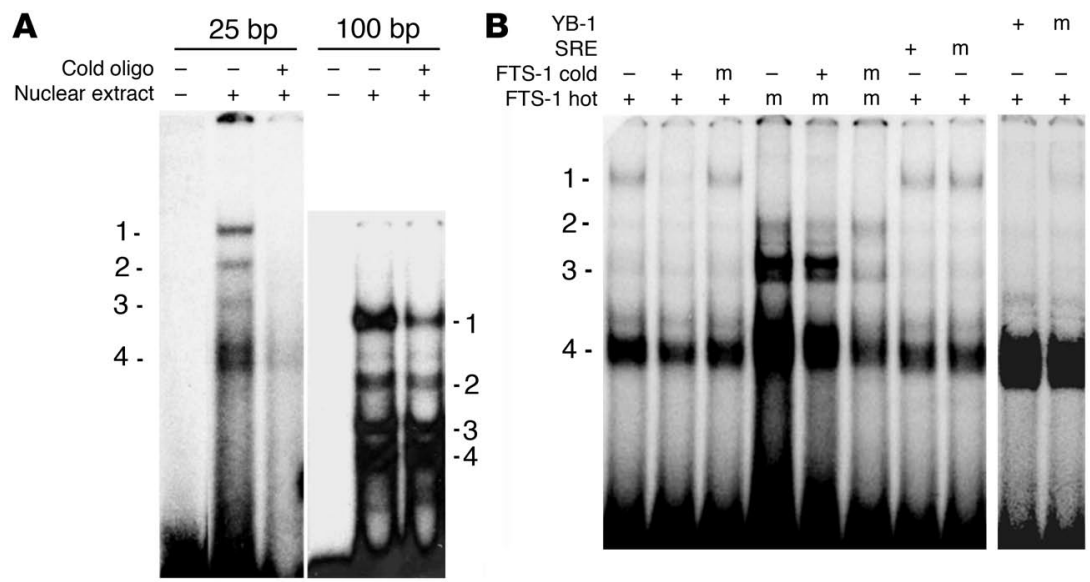

\section{Figure 1}

Identification and purification of the FTS-1 complex by EMSA and DNA affinity chromatography. (A) Similar complexes form in EMSA with fibroblast nuclear protein and either 25-bp or 100-bp probes, both containing the FTS-1 core pentanucleotide. The complexes were challenged with nonlabeled probes. (B) Specificity of the FTS-1 complex established by EMSA following challenge by various nonlabeled competitors. Fibroblast nuclear protein was incubated with the 25 -bp radiolabeled FTS-1 or its mutant form $(m)$. The complexes were challenged with DNA probes specific for different regulatory sites. The complex specific to the TTGAT pentanucleotide (marked 1 ) is at the top; $(\mathrm{m})$ indicates the mutated oligonucleotides. (C) The FTS-1 complex (marked 1) is formed by MCT cells induced to EMT as evidenced by EMSA at different times after induction. A fibroblast-derived FTS- 1 complex is shown as a positive control. (D) DNA affinity-purified proteins form only 1 complex with FTS-1 (marked 1) in EMSA. Fractions purified by the direct or indirect approach were eluted with $0.5 \mathrm{M} \mathrm{KCl}$ followed by $0.5 \mathrm{M} \mathrm{KCl}$ plus $5 \mathrm{M}$ urea, dialyzed against $0.1 \mathrm{M} \mathrm{KCl}$, and incubated with radiolabeled FTS- 1 or its mutated form $(\mathrm{m})$. The flow-through (FT) from the direct incubation could not form the FTS-1 complex.

using related and unrelated probes (Figure 1B). Complexes formed with radiolabeled FTS- 1 or its mutant (CCAGC instead of TTGAT) were competed at $20 \times$ molar excess with unlabeled species or with consensus sites for the Y-box transcription factor (YB-1) and serum response factor (SRE). The YB-1 core sequence differs in 1 nucleotide from FTS-1 (TTGGT versus TTGAT), and SRE is unrelated to FTS- 1 and contains a CarG box DNA motif. Mutant constructs of these oligonucleotides were also used in the competition analysis. Of the 4 complexes formed by the FTS- 1 probe, the more slowly migrating complex 1 was not competed by its mutant and the only one not formed by a radiolabeled mutant. Complex 1 was competed by YB-1 because of structural similarity, but when used as a probe, YB-1 did not form a similar complex in EMSA (data not shown). Complex 1 was also unaffected by challenge with the YB-1 mutant or SRE. Competition analysis confirmed this complex as specific for the core FTS-1 site (TTGAT). Unlabeled competitors did not affect complex 4. Complexes 2 and 3, although not competed by YB-1 or by SRE, were formed with both FTS-1 and its mutant (Figure 1B). Therefore, only complex 1 was specific for FTS-1. Complex 1 also formed in EMSA when the probe was incubated with nuclear extracts from kidney epithelial cells undergoing EMT (Figure 1C) in parallel with the expression of FSP1 (6).

These results were confirmed in another epithelial cell line from mouse inner medullary collecting duct (mIMCD; ref. 28). mIMCD cells stimulated to undergo EMT with TGF- $\beta /$ EGF formed FTS- 1 complexes on day 5 (data not shown).

The FTS-1-binding complex identified by EMSA was purified independently using DNA affinity chromatography. We used a biotinylated tetramer of the 25 -bp FTS- 1 sequences attached to streptavidin-coated magnetic beads. The binding reactions were performed under the same conditions as the EMSAs to ensure comparability. Initially we used 2 experimental variants: a direct incubation of nuclear extracts with the FTS-1 oligonucleotide; and an indirect approach using the flow-through from an initial incubation with the mutant tetramer for a secondary incubation with the TTGAT tetramer. Proteins that bind specifically were eluted with high salt, with or without urea, and analyzed by EMSA using radiolabeled mutant or wild-type FTS-1 (Figure 1D). The results of this analysis demonstrate that affinity-purified proteins were able to form a DNA-protein complex, which comigrated with complex 1 . There was no difference in the complexes formed by the proteins purified by either approach, and subsequently we used only the indirect approach to minimize contaminating proteins. These results established that both EMSA and DNA affinity chromatography consistently identified the same FTS-1 complex. The complex recovered both from EMSA and from DNA affinity purification was used separately for protein identification utilizing tandem mass spectrometry (25).

Proteomic analysis of FTS-1 complexes. The combination of EMSA with mass spectrometry identified several protein signatures. Two independent peptides from the FTS-1 complex (Table 1) were identified as CBF-A (26). Two other peptides belonged to the tripartite motif protein 28 (TIF1 $\beta /$ Trim28), a mouse homolog of KAP-1 (27). Other identified peptides were from the eukaryotic elongation factor $1 \alpha 1$ (EEF1A1) and the DNA replication-licensing factor MCM3.

A second technique, DNA affinity chromatography followed by mass spectrometry, also identified CBF-A and KAP-1 in the FTS-1 complex. Three independent CBF-A peptides were identified; 


\section{Table 1}

Peptide identification in the FTS-1-binding complex

\begin{tabular}{|c|c|c|c|}
\hline \multirow[t]{2}{*}{ Protein } & \multirow[t]{2}{*}{ Accession no. } & \multicolumn{2}{|c|}{ Peptide sequence } \\
\hline & & Purification by EMSA & Purification by DNA affinity chromatography \\
\hline CBF-A & Q99020 & GFVFITFKEEDPVK, IFVGGLNPEATEEK & $\begin{array}{c}\text { GFVFITFKEEDPVK, IFVGGLNPEATEEK, } \\
\text { EVYQQQQYGSGGR }\end{array}$ \\
\hline $\begin{array}{l}\text { Tripartite motif protein } 28 \\
\text { (TIF1 } \beta / \text { Trim28)/KAP-1 }\end{array}$ & Q62318 & $\begin{array}{l}\text { EEDGSLSLDGADSTGVVAK, } \\
\text { LDLDLTSDSQPPVFK }\end{array}$ & $\begin{array}{l}\text { EEDGSLSLDGADSTGVVAK, } \\
\text { LDLDLTSDSQPPVFK }\end{array}$ \\
\hline EEF1A1 (EF-1 $\alpha 1 /$ EF-Tu) & P10126 & $\begin{array}{l}\text { EHALLAYTLGVK, IGGIGTVPVGR, RYEEIV } \\
\text { STTTGHLIYK, THINIVVIGHVDSGK, YYVTIIDA }\end{array}$ & None \\
\hline
\end{tabular}

2 are shared by both purification approaches, and a third one, EVYQQQQYGSGGR, appeared in the affinity-purified complex (Table 1). The 2 KAP-1 peptides described above were also confirmed. However, neither EEF1A1 nor MCM3 peptides were present in the affinity-purified complex.

We used 2-dimensional EMSA/SDS-PAGE followed by immunoblotting to further characterize the composition of the FTS-1 complex. To this end, we ran nuclear extracts in EMSA with and without incubation with an FTS-1 probe and then subjected the gel pieces to second-dimension SDS-PAGE. After subsequent transfer to membrane and immunostaining, we confirmed the presence of CBF-A and KAP-1 in the FTS-1 complex (Figure 2A). Immunostaining indicated the absence of CBF-A and KAP-1 in control extracts, as shown on the left side of each panel. Only MCM3-positive immunostaining was detected on the left side of the panel (data not shown), which suggests this latter protein does not form a complex with FTS-1 and only comigrates with the complex in the first dimension. An antibody against EEF1A1 did not detected it either in the complex or as a comigrating protein, suggesting it was an artifact.

The binding of CBF-A and KAP- 1 to the FTS- 1 probe was confirmed additionally by EMSA supershifts (Figure 2B). The CBF-A antibody supershifts the FTS- 1 complex, while antibody against KAP-1 abolishes it. We suspect the KAP-1 antibody most likely inhibits sterically the interaction of CBF-A/KAP-1 with FTS-1. Anti-rabbit IgG did not affect the mobility or integrity of the FTS-1 complex. Finally, we performed a chromatin immunoprecipitation (ChIP) assay with the CBF-A antibody using a rabbit preimmune serum as a negative control. Western blots of precipitates (Figure 2C) confirmed the presence of both CBF-A and KAP-1 as participating in a complex with FTS-1. The increased expression of CBF-A and KAP-1 in cell nuclei during EMT was further demonstrated by immunostaining MCT epithelia stimulated with TGF- $\beta$ and EGF in culture (6); the nuclear staining for CBF-A increased from $14.8 \%$ of cells in unstimulated epithelia to $47.9 \%$ in EMT-induced fibroblasts, and nuclear KAP-1 levels increased from 3.3\% to $30.2 \%$ (Figure 2D). These data collectively suggest that CBF-A and KAP-1 are components that recognize the FTS-1 element in cell nuclei.

rCBF-A induces de novo expression of FSP1 in kidney epithelial cells. Differentiated epithelial cells do not express FSP1 nor form nuclear complexes with FTS-1 (24). When they undergo EMT, however, they form FTS-1 complexes (Figure 1C) and synthesize FSP1 (6). To understand the functional significance of CBF-A in the induction of FSP1, we expressed recombinant CBF-A (rCBF-A) in epithelial cells. For this purpose, the kidney epithelial cell line MCT was stably transfected with a TET-inducible vector for conditional expression of $r C B F-A(\mathrm{MCT} / \mathrm{rCBF}-\mathrm{A})$. We selected several clones that displayed controlled overexpression of $r C B F-A$ following exposure to doxycycline. We refer to the noninduced state as MCT/ rCBF-A ${ }^{-}$and to the doxycycline-induced state as MCT/rCBF-A ${ }^{+}$. The induction of $r C B F-A$ with doxycycline led to the expression of FSP1 transcripts (Figure 3A) and the coordinate appearance of FSP1 protein (Figure 3D). Overexpression of $r C B F-A$ resulted in the formation of the FTS-1 complex, as confirmed by ChIP assay with CBF-A and KAP-1 antibodies (Figure 3B). Noninduced cells maintain low levels of endogenous CBF-A, and the FTS-1 DNA site could not be detected by PCR. However, cells induced with doxycycline formed FTS-1 complexes robustly (Figure 3B). Chromatin from 3T3 fibroblasts was immunoprecipitated in parallel as a positive control (Figure 3B, left), with comparable results. Furthermore, nuclear extracts from $\mathrm{MCT} / \mathrm{rCBF}-\mathrm{A}^{+}$cells, but not from wild-type MCT cells, formed the FTS- 1 complex in EMSA with affinity similar to that of extracts from $3 \mathrm{~T} 3$ fibroblasts, as demonstrated by challenge with increasing molar amounts of unlabeled competitor (Figure 3C). These results indicate that overexpression of $r C B F-A$ leads to formation of the FTS- 1 complex and activation of FSP1 expression in epithelia in much the same way as FSP1 is expressed by fibroblasts.

We further confirmed these findings in an in vivo kidney model of EMT and fibrosis following unilateral ureteral obstruction (UUO) (4). Obstructed kidneys undergoing EMT and fibrosis after 12 days (data not shown) had increased levels of CBF-A, FSP1, and $\alpha$-SMA $(P<0.002$; Figure 3E). This increase in CBF-A and FSP1 was accompanied by an expected decrease in E-cadherin expression. The expression of the other protein in the FTS-1 complex, KAP-1, was slightly upregulated in the UUO kidney, but the increase was not statistically significant.

Figure $3 \mathrm{~F}$ demonstrates a change in the nuclear localization of CBF-A in fibrotic renal tissue 12 days after UUO in FSP1.GFP mice. CBF-A in the normal contralateral kidney was observed in the cytoplasm (speckled green) of tubular cells (nuclei counterstained red with propidium iodide); FSP1 ${ }^{+}$fibroblasts expressing GFP under the control of the FSP1 promoter were recolored dark blue in these images. In the frames labeled UUO1 and UUO2, the red nuclei have become yellow/orange with a change in localization of CBF-A from the cytoplasm (percentage of nuclei stained for CBF-A increased $21 \%$ in obstructed kidneys compared with $4 \%$ in contralateral controls; $P<0.0001$ ), and the fibroblasts now stained light blue with the addition of CBF-A. This series of images suggests that the nuclei of many tubular cells in the UUO kidney are enriched for CBF-A and potentially positioned for an EMT event. The upregulation of CBF-A in UUO kidney established by quanti- 

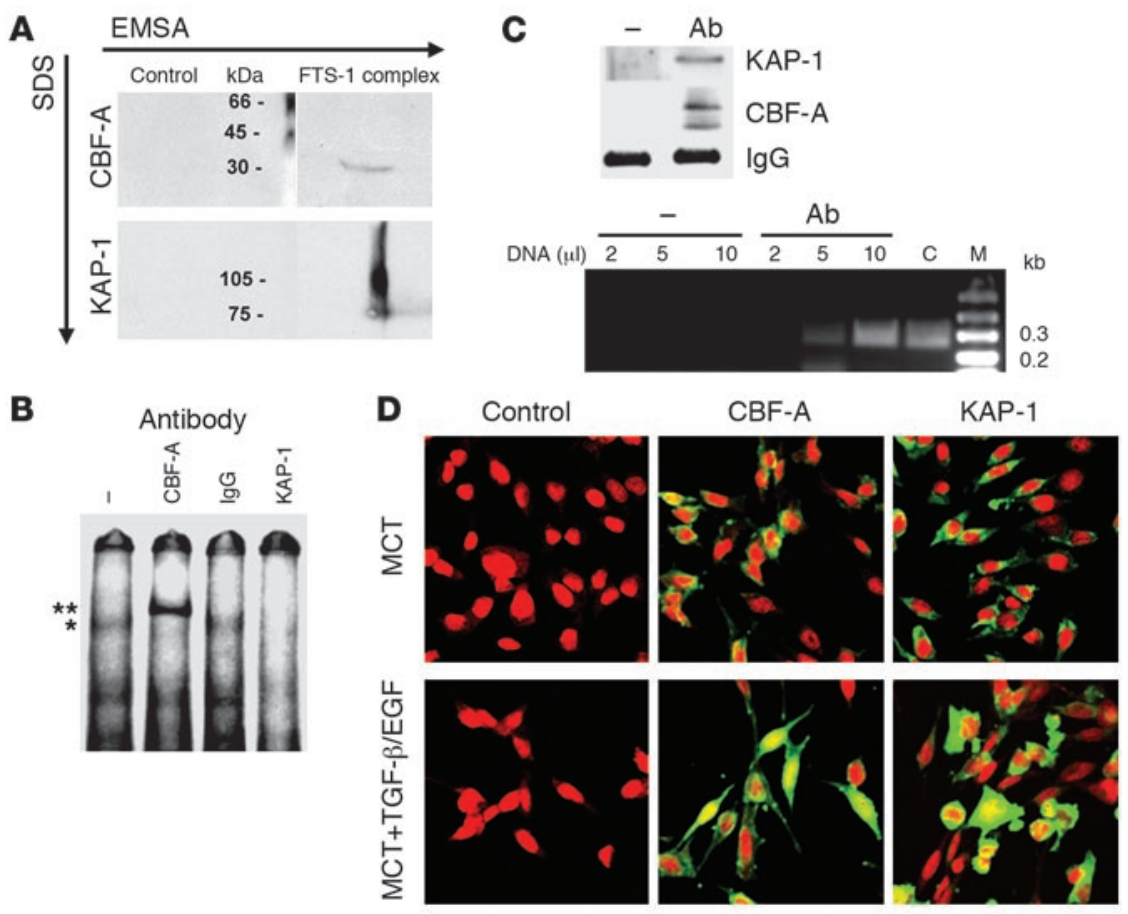

Figure 2

CBF-A and KAP-1 are integral parts of the FTS-1 complex. (A) Immunoblotting and 2D electrophoresis. First dimension: EMSA; second dimension: SDS-PAGE. Left: control for EMSA with nuclear protein without the probe; right (FTS-1 complex): protein with the FTS-1 probe. The absence of immunostaining on the left indicates that the investigated proteins do not comigrate with the complexes in the absence of DNA. (B) The participation of CBF-A and KAP-1 in the FTS-1 complex was confirmed by EMSA with their antibodies. The complex (*) was supershifted by the CBF-A antibody as indicated $\left(^{* *}\right)$ and was abolished by anti-KAP-1 antibody; rabbit IgG did not affect the complex. (C) ChIP of 3T3 chromatin with the anti-CBF-A antibody or rabbit preimmune serum (-). Western blotting (upper panel): the immunoblots were probed with antibodies against KAP-1 and CBF-A; the stained IgG is shown as a loading control. PCR (lower panel): Increasing amounts (2, 5, and $10 \mu \mathrm{l})$ of DNA eluted from the immunoprecipitates were used as template in PCR with primers encompassing the FTS-1 site in both directions, producing a fragment of approximately $280 \mathrm{bp}$. Genomic DNA from 3T3 fibroblasts was used in the PCR as a positive control. M, DNA size ladder in kilobases (kb). (D) After induction of EMT, MCT cells showed increased nuclear colocalization of KAP- 1 and CBF-A. MCT epithelia were stimulated for 5 days with TGF- $\beta / E G F$ in culture. Cells were stained with nuclear propidium iodide dye (red) followed by indirect immunofluorescence with primary antibodies against CBF-A or KAP-1 or with control FITCanti-rabbit IgG alone. Original magnification, $\times 630$.

tative real-time PCR (qRT-PCR) analysis (Figure 3E) suggests that most of the nuclear protein is newly synthesized.

Overexpression of CBF-A engages the fibroblast transcriptome by initiating EMT. Treatment of cultured epithelia with a combination of EGF and TGF- $\beta$ initiates EMT (6), which is associated with the activation of fibroblast markers such as FSP1, vimentin, and $\alpha$-SMA and a downregulation of E-cadherin and the tight junction-associated protein zona occludens 1 (ZO-1); the induction of FSP1 precedes the emergence of the EMT phenotype and the capacity of epithelia for movement, indicating a key early role for FSP1. A similar induction of FSP1 in MCT/rCBF-A ${ }^{+}$cells (Figure $3 \mathrm{D}$ ) suggests that $r C B F-A$ is sufficient to initiate EMT. We further checked for levels of expression of a number of other epithelial and fibroblast cell markers in MCT/rCBF-A $\mathrm{A}^{+}$cells, as well as their cell motility and morphology. Results from immunoblotting indicate that MCT/ rCBF- $\mathrm{A}^{+}$cells have increased levels of the fibroblast markers FSP1,

\section{Discussion}

$\alpha$-SMA, vimentin, and $\alpha 1(\mathrm{I})$ collagen, together with the newly identified markers of EMT, $\mathrm{N}$-cadherin, Snail, and Twist (Figure 3D). The latter 2 proteins are transcription factors associated with increased motility of transitional epithelial cells $(11,20)$. The levels of E-cadherin, $\beta$-catenin, and $\mathrm{ZO}-1$ were attenuated correspondingly. These changes in protein levels are indicative of cell remodeling associated with $\operatorname{EMT}(1,2)$.

The differential expression of epithelial and fibroblast markers induced by $r C B F-A$ was confirmed by changes in levels of mRNA (data not shown) and by immunostaining of $\mathrm{MCT} / \mathrm{CBF}-\mathrm{A}^{+}$compared with control epithelial cells 5 days after induction (Figure $4 \mathrm{~A})$. The pattern of expression and distribution of ZO- $1, \beta$-catenin, $\alpha$-SMA, and vimentin in MCT/CBF-A $\mathrm{A}^{+}$cells clearly indicates a change of phenotype associated with FSP1 expression. Furthermore, 5 days following the induction of $r C B F-A, \mathrm{MCT} / \mathrm{rCBF}-\mathrm{A}^{+}$cells but not control cells assumed a spindle-like, fibroblast morphology typical of epithelial transition (Figure 4B).

The change in phenotype induced by $r C B F-A$ was associated with an increased ability of $\mathrm{MCT} / \mathrm{rCBF}-\mathrm{A}^{+}$fibroblasts to migrate directionally following serum stimulation in a Boyden chamber assay (Figure 4C). Conversely, inhibition of CBF-A expression in 3T3 fibroblasts by siRNA caused a coordinated downregulation of CBF-A and FSP1 proteins (Figure 5). Transiently transfected siRNA1 best inhibited $C B F-A$ and FSP1 expression after 48 hours by qRT-PCR from 3 independent experiments; $37 \%$ and $49 \%$, respectively $(P \leq 0.001)$. These data collectively indicate that overexpression of $r C B F-A$ in epithelial cells leads to formation of the FTS- 1 complex, expression of FSP1, modulation of epithelial and fibroblast genes including Snail and Twist, and subsequent EMT.

In this study, we have discovered what we believe to be a new set of transcriptional proteins mediating early events in EMT. As an experimental probe, we used a novel promoter element (FTS-1) found in the gene encoding FSP1 to identify a novel complex of transcriptional proteins, CBF-A and KAP-1, which engage the genes encoding the EMT proteome. We conclude the following: first, CBF-A and KAP-1 can be found in a complex with the FTS-1 element in fibroblasts and in epithelia and tissues undergoing EMT; second, occupancy of the FTS-1 site by these proteins in the chromatin of transitioning epithelia correlates with the activation of the EMT proteome; and third, the expression of recombinant $C B F-A$ initiates key, early transcriptional and phenotypic events in EMT (see schematic in Figure 6).

The first component we found bound to FTS- 1 was originally cloned as the CarG box-binding protein called CBF-A (26) - not 


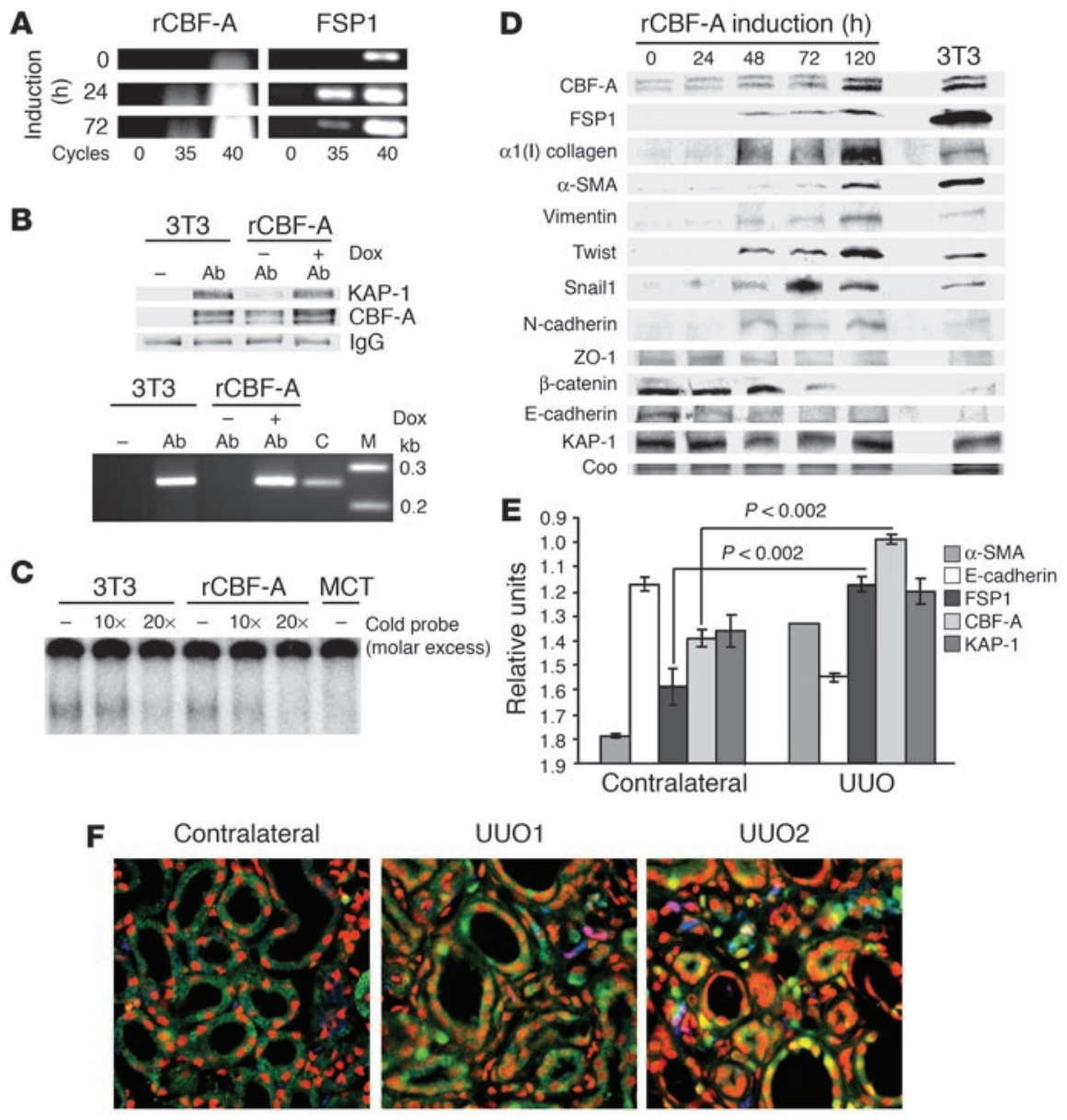

Figure 3

Overexpression of CBF-A in the epithelial cells leads to formation of the FTS-1 complex and expression of fibroblast markers. (A) Transcripts for $r C B F-A$ and FSP1 increase in PCR cycles after $r C B F-A$ induction. (B) ChIP assay shows formation of the FTS-1 complex in epithelial cells expressing rCBF-A (+Dox; doxycycline) compared to 3T3 cells. IgG was a loading control. Immunoprecipitated DNA was used in PCR with primers for FTS-1. (C) Nuclear protein from $\mathrm{MCT} / \mathrm{rCBF}-\mathrm{A}^{+}$or $3 \mathrm{~T} 3$ fibroblasts form FTS-1 complexes in EMSA with similar affinity, challenged by $10 \times$ or $20 \times$ molar excess of nonlabeled FTS -1 probe (Cold probe). MCT cells were the negative control. (D) Differential expression of epithelial and mesenchymal protein markers in $\mathrm{MCT} / \mathrm{rCBF}-\mathrm{A}^{+}$cells at different hours after induction of rCBF-A compared with $3 \mathrm{~T} 3$ fibroblasts. Coo, Coomassie staining. (E) Increased expression of CBF-A and FSP1 in UUO undergoing EMT (28\% and $26 \%$, respectively) as measured by qRT-PCR and represented graphically in arbitrary units. Included for comparison are E-cadherin, $\alpha$-SMA, and KAP-1. (F) CBF-A (yellow/orange) accumulates in the nuclei of tubular and interstitial cells from the UUO kidney in FSP1.GFP mice. FSP1+ fibroblasts expressing GFP under the control of the FSP1 promoter were recolored dark blue, and nuclei were counterstained red. Normal contralateral kidney tissue demonstrates CBF-A in the tubular cytoplasm (speckled green). In the cytoplasm, CBF-A and FSP1 staining merge to become light blue. Original magnification, $\times 630$. no sequence similarity between FTS-1 and the canonical CarG box sequence (CC $\left.[\mathrm{AT}]_{6} \mathrm{GG}\right)$, and moreover, the SRE containing a canonical CArG box element does not compete the FTS-1 complex. CBF-A has also been described both as conditional repressor (34) or activator of the Ha-ras response element (35) and as an activator of the rat spi 2 gene (36) via a GAGA box. CBF-A also binds an AT-rich promoter element in immunoglobulin kappa genes (37) and stabilizes a specific tetraplex telomeric DNA sequence (38). Thus, the overwhelming evidence implicates CBF-A as a transcriptional regulator and/or structural component of chromatin. However, remarkably, CBF-A contains no recognizable DNA binding motif for FTS-1.

CBF-A also belongs to the heterogeneous nuclear ribonucleoprotein (Hnrpab) subfamily A/B (hnRNP A/B). It contains 2 evolutionarily conserved RNA recognition motifs found in many RNA-binding proteins, functions as an mRNA-editing protein (39), and mediates the stability of proinflammatory mRNAs by binding to the AU-rich element (40). As a complex with actin, it is involved in nuclear-cytoplasmic transport of mRNA (41). Androgen-regulated posttranslational modification of CBF-A is also associated with cytoskeletal changes in a mouse fetal cell line, which may have been unrecognized EMT (42). Finally, CBF-A is upregulated in some mammary tumors (43) and in solid tumor metastasis (44). Depending on the context, CBF-A appears to be a "moonlighting" protein (45). It activates or represses transcriptional and posttranscriptional events, with a particularly important role in EMT. Finally, by inference, the association of EMT with metastatic conversion (13) together with reports of elevated levels of CBF-A in metastasis $(43,44)$ and its role in the transactivation of the Ha-ras protooncogene (35) suggests a possible role in carcinogenesis. These properties are completely consistent within our identification of CBF-A as a regular of EMT (13).

The second protein identified in the FTS-1 to be confused with other proteins named similarly: the CBF-binding intronic enhancer (29), Cbfa1/osteoblast-specific factor 2 (30), the core binding factors (CBFs) (31), PEBP2/CBFA1 (30), CCAATbinding factor $\alpha$ (CBF-A) (32), and the hematopoietic transcription factor CBFA2 (33).

Multiple nucleic acid binding activities have been attributed to CBF-A, although its ability to bind a DNA duplex with sequence homology to FTS-1 has not been previously demonstrated. As a CArG box-binding protein, it was originally described as a transcriptional repressor of the $\alpha S M A$ promoter (26). There is complex, KAP-1, is a well-studied transcriptional repressor that binds to KRAB domains on zinc finger proteins (27). The transcriptional repressor function of KAP-1 is mediated through its interaction with the heterochromatin-associated protein HP1 $(46,47)$ and with a specific histone methyltransferase, SETDB1, that contributes to the silencing of actively transcribed genes in euchromatin $(48,49)$. It is surprising, but intriguing, that the KAP-1 corepressor is present in our nucleoprotein complex that functions to activate transcription. Moreover, previous studies of KAP-1 have shown it to be almost exclusively bound to KRAB-zinc finger proteins in 

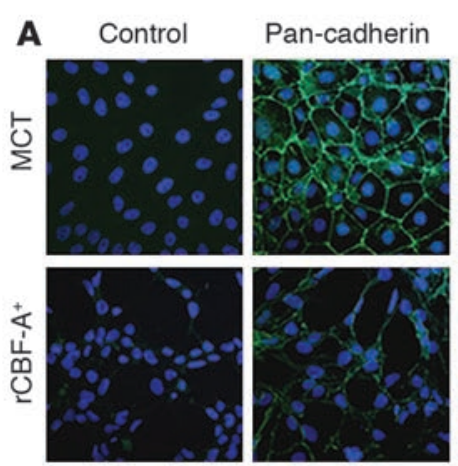

B
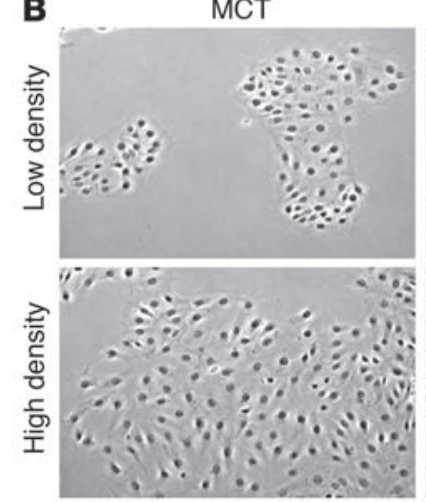

-catenin
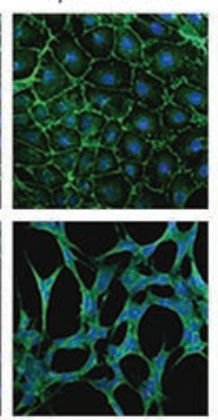

ZO-1
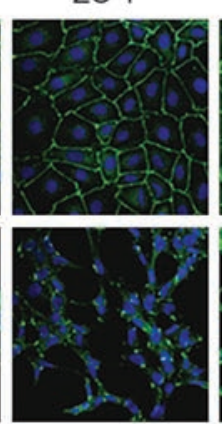

F-actin
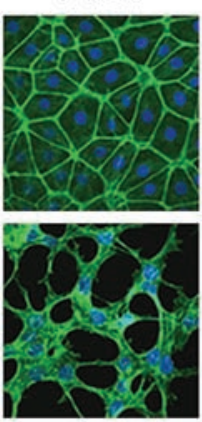

Vimentin
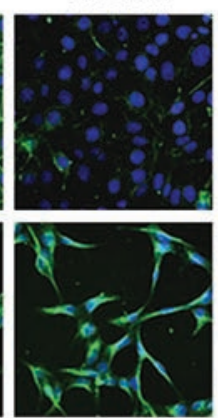

FSP
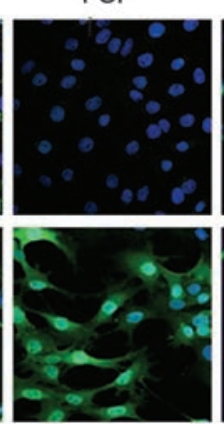

$\alpha-S M A$
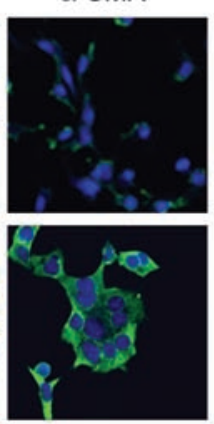

C

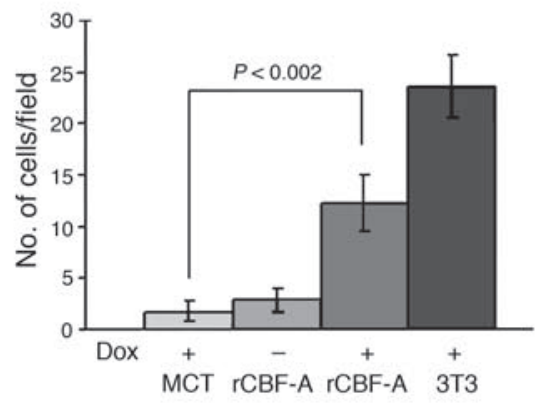

Figure 4

Inducible expression of $r C B F-A$ in MCT epithelial cells leads to induction of FSP1, changes in the expression pattern of cell type markers, and acquisition of mesenchymal phenotype. (A) Immunostaining with cell type markers of naive epithelium (MCT) and of cells expressing rCBF-A. Results of staining with isotype IgG are included (Control). Original magnification, $\times 630$. (B) Morphological changes in MCT/rCBF-A $\mathrm{A}^{+}$compared with MCT cells at day 5 of $r C B F-A$ induction. Cells are shown at both high and low density. Original magnification, $\times 200$. (C) Increased motility of cells expressing $r C B F-A\left(r C B F-A^{+}\right)$after doxycycline induction as compared with rCBFA ${ }^{-}$and control MCT cells. 3 T3 fibroblasts were included in this Boyden chamber assay as positive control. The average number of migrating cells is represented graphically and evaluated statistically.

vivo. However, our ChIP data conclusively show that both CBF-A and KAP-1 are present at the endogenous CBF-A site. There are a number of possibilities that may reconcile this new finding: first, there is evidence that the RNA recognition motif (RRM) in CBF-A may interact with the PHD domain of KAP-1 $(50,51)$. Thus, CBF-A and KAP-1 may form a physical complex that converts KAP-1 into a coactivator. We have recent evidence that posttranslational modification by SUMO regulates the repressor activity of KAP-1, thus providing a mechanism for toggling between activation and repression (unpublished observations). Second, and alternatively, an as-yet-unidentified KRAB-zinc finger protein may bind FTS-1 and tether KAP-1 to the site. Subsequently, the KAP-1 protein may remain associated with the chromatin after release of the putative $\mathrm{KRAB}$-zinc finger protein during EMT activation. Third, CBF-A may be bound to a protein such as nucleophosmin, as has been recently described for the immunoglobulin kappa promoter (52). These findings open the possibility that the promoter-binding effect of CBF-A can be regulated by its interaction with various protein partners. The interaction of CBF-A with KAP1 may confer such specificity for binding the FTS-1 promoter element in epithelia transitioning to fibroblasts. How KAP-1 modulates this interaction is not yet known.

A key finding of this study is that $r C B F$ - $A$-triggers expression of the EMT proteome in epithelia that parallels the changes in pheno- type and potential for motility, all characteristics compatible with a fibroblast phenotype. Several other transcription proteins are also expressed during EMT. Twist (11), HMGA2 (21), and Snail (53) repress E-cadherin and induce EMT in epithelia, although loss of E-cadherin alone is not sufficient to initiate EMT (54). A recent report also suggests that gelsolin functions as a switch that controls conversion of E-cadherin to N-cadherin via Snail, and gelsolin's inhibition triggers EMT (55). Ets-1 (56) and Rho-related proteins (57) are also involved in this process. The fact that different transcriptional regulators can independently induce EMT suggests multifunctionality to molecular activation that may depend on the context of cytokine signaling events or changes in cytoskeletal structure that force cells into transition (1). Since metastatic tumor cells employ the same molecular program for EMT as that used by epithelia converting to fibroblasts (13), the FTS-1 complex is likely used by different epithelia to ensure phenotypic transitions.

Several potential binding sites for transcription factors have been identified in genes implicated in the EMT transcriptome, and our in silico search of the promoter regions of these genes upstream of transcriptional start site are summarized in Table 2. The E-box motifs are present only in 2 genes repressed in EMT, E-cadherin and gelsolin, but not in ZO-1 or $\beta$-catenin, where expression is equally attenuated. The CArG box motif is present in the repressed gene encoding E-cadherin but is also present 


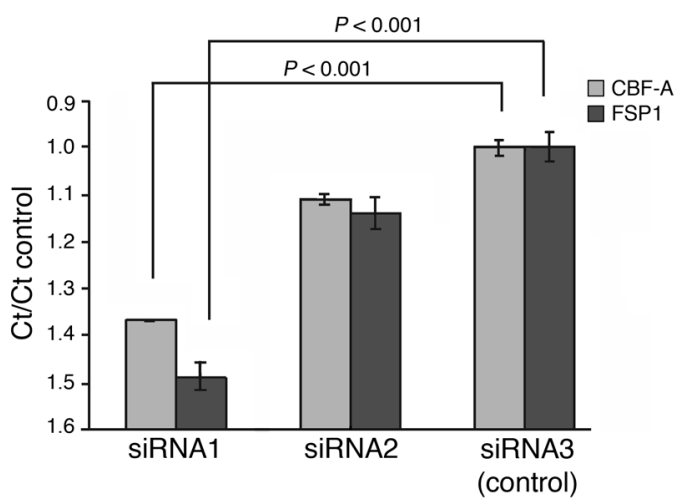

Figure 5

Inhibition of CBF-A transcripts by siRNA downregulates expression of $F S P 1$ transcripts. Three synthetic ribonucleotides were transfected into 3 T3 fibroblasts, and the effect was monitored by qRT-PCR at different time points. The $\mathrm{Ct}$ values for transcripts encoding $C B F-A$ and $F S P 1$ at the 48-hour time point obtained in triplicate were normalized to those for GAPDH. As siRNA3 did not attenuate the expression of either gene, the data were expressed as ratios to this reference control; siRNA1 best inhibited transcripts encoding CBF-A and FSP1 compared with siRNA3; $P<0.001$. Presented are combined results from 3 separate experiments.

in the activated gene encoding $\alpha$-SMA. The lymphoid enhancing binding factor (LEF-1) binding site is also shared by up- and downregulated genes, reflecting perhaps the context-dependent effect of LEF-1. The most abundant regulation site is FTS-1, which again is evenly distributed among differentially expressed genes in EMT. It is likely that a specific combination of these sites is necessary to achieve differential expression in the EMT transcriptome. Accordingly, the promoter regions of Twist, Snail, HMGA2, LEF-1, and Ets1 each contain FTS-1 sites, but not CArG- or E-box motifs (Table 2). Our findings implicate FTS- 1 as a critical site that in combination with other cis-acting elements regulates the EMT transcriptome across a broad range of promoters.

In summary, this study reveals a mechanism for transcriptional activation of EMT using the interaction of FTS-1 sites with CBF-A and KAP-1. The finding that the CBF-A/KAP-1/ FTS- 1 complex is an activator of the genes encoding the EMT proteome suggests that it is an early proximal regulator, if not a candidate master gene, in the molecular program leading to fibroblast formation. This discovery has important implications for EMT-dependent biological processes, including organ fibrosis and metastatic cancer. CBF-A may be a good target candidate for suppressing EMT under pathologic circumstances.

\section{Figure 6}

This schematic, based on assumptions derived from the current data, shows CBF-A as a proximal transcription factor induced by outside-inside signaling. Migration to the nucleus causes the formation of CBF-A/KAP-1/FTS-1 binding complexes, which can activate other known transcriptional regulators of EMT, including Snail, Twist, HMGA2, LEF-1, and Ets-1. These are not the only EMT-related genes that are activated by CBF-A/KAP-1/FTS-1 binding complexes (see Table 2), but they could account for the activation of most of the known and well-studied transcriptional regulators of EMT. ILK, integrin-linked kinase.

\section{Methods}

Cell cultures. NIH 3 T3 cells were used as a source of mouse fibroblasts. Cells of the kidney proximal tubular epithelial cell line MCT were derived from SJL/J mice (58). mIMCD cells were a gift from Raymond Harris (Vanderbilt University, Nashville, Tennessee, USA). Cell cultures were maintained as described previously (6). For induction of EMT in culture, epithelial cells were treated with $3 \mathrm{ng} / \mathrm{ml}$ of TGF- $\beta$ and $10 \mathrm{ng} / \mathrm{ml}$ of EGF in standard culture media (6). The progress of EMT was monitored by phenotypic observation, cell motility assays, PCR, immunoblotting, or immunochemistry at different time points for up to 5 days after induction.

UUO. Three-month-old male BALB/c mice (The Jackson Laboratory) or FSP1.GFP mice on a BALB/c background were anesthetized according to our surgical protocol, and the right ureter was ligated at 2 points (4). Both fibrotic and normal contralateral kidneys were harvested 12 days after surgery and either snap-frozen in liquid nitrogen or fixed in $4 \%$ of paraformaldehyde. RNA was extracted from crushed frozen tissue by homogenization in TRIzol (Invitrogen), and after DNAse I treatment and inhibition (Ambion), 5- $\mu \mathrm{g}$ aliquots of RNA were used in a reverse transcription reaction with SuperScript reverse transcriptase (Invitrogen). The resulting cDNA was used as template for qRT-PCR analysis. Primers/probes for CBF-A, FSP1, E-cadherin, $\alpha$-SMA, KAP-1, and GAPDH were obtained from TaqMan Gene Expression Assays (Applied Biosystems). Gene quantification was performed in triplicate on the Applied Biosystems 7900HT Fast Real-Time PCR System. Data were expressed in threshold cycle $(\mathrm{Ct})$ values normalized against corresponding GAPDH expression. The Institutional Animal Care and Use Committee (IACUC) at Vanderbilt University approved all animal studies.

Immunobistochemistry, immunofluorescence, and immunoblotting. Polyclonal anti-KAP-1 antibody was prepared by Frank Rauscher (Wistar Institute, Philadelphia, Pennsylvania, USA); the antibody against CBF-A was kindly provided by Jonathan Dean, Imperial College of Science, London, United Kingdom; anti-pan-cadherin and anti- $\alpha$-SMA antibodies were from

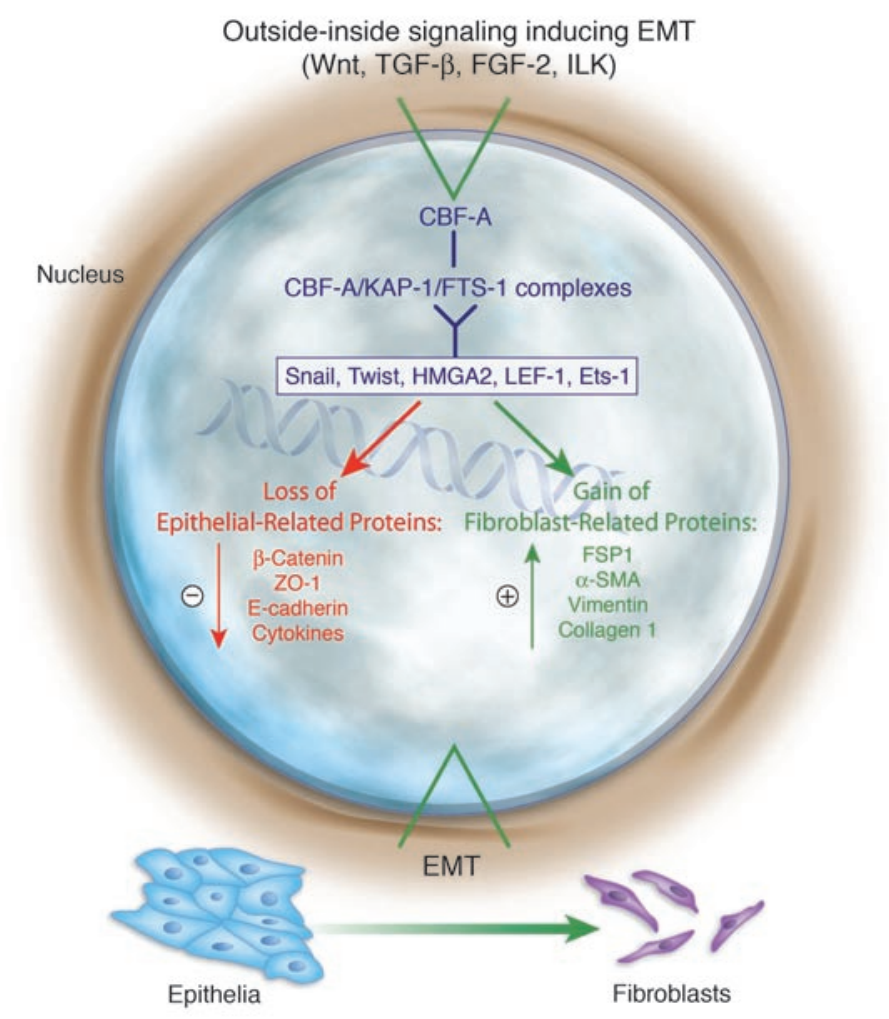


Table 2

Selected promoter sites in the EMT transcriptome

\begin{tabular}{|c|c|c|c|c|}
\hline Genes & FTS-1 & CArG & E-box & LEF-1 \\
\hline$\alpha$-Skeletal actin & 3 & - & - & - \\
\hline$\alpha-S M A$ & 1 & 1 & - & 1 \\
\hline Annexin 8 & 1 & - & - & - \\
\hline$\beta$-Catenin & 2 & - & - & - \\
\hline$\alpha 1(I)$ collagen & - & - & - & 1 \\
\hline$\alpha 2(I)$ collagen & 3 & 2 & - & - \\
\hline Desmoplakin & 2 & - & - & - \\
\hline E-Cadherin & 1 & 1 & 1 & 1 \\
\hline Ets-1 & 3 & - & - & - \\
\hline$L E F-1$ & 1 & - & - & - \\
\hline FSP1 & 2 & - & - & - \\
\hline Smad2, Smad3 & - & - & - & - \\
\hline Gelsolin & 1 & - & 1 & - \\
\hline HMGA2 & 1 & - & - & - \\
\hline Laminin B3 & 2 & - & - & 1 \\
\hline Lamin A & 3 & - & - & - \\
\hline MMP-9 & 2 & - & - & - \\
\hline Moesin & 5 & - & - & - \\
\hline Rho & 3 & - & - & 1 \\
\hline Snail & 3 & - & - & 1 \\
\hline Slug & - & - & - & - \\
\hline Twist & 4 & - & - & - \\
\hline Vimentin & 4 & - & - & - \\
\hline$Z O-1$ & 3 & - & - & - \\
\hline
\end{tabular}

Sigma-Aldrich; antibodies against Collagen I, Vimentin, Twist, Snail-1, $\mathrm{N}$-cadherin, ZO-1, $\beta$-catenin, and E-cadherin were from Santa Cruz Biotechnology Inc. Immunohistochemistry, immunofluorescence, and immunoblotting were performed as described previously $(13,59)$. Propidium iodide $(0.1 \mu \mathrm{g} / \mathrm{ml})$ (Molecular Probes; Invitrogen) and $1.0 \times 10^{-8} \mathrm{M}$ TRITC-conjugated phalloidin (Sigma-Aldrich) were used to stain nuclei and filamentous actins. Isotype variants were included as a negative control. Confocal fluorescence intensity was measured using the NIH Image program (http://rsb.info.nih.gov/nih-image). Image and data analysis were performed using the Vanderbilt University Medical Center Cell Imaging Core Resource.

ChIP. ChIP assays were performed using reagents from Upstate USA Inc. according to the manufacturer's protocol with the following modifications. Cross-linking by formaldehyde ( $1 \% \mathrm{vol} / \mathrm{vol})$ was done directly in cultured fibroblasts or MCT/rCBF-A cells for 10 minutes at $37^{\circ} \mathrm{C}$ and terminated by glycine at a $0.125-\mathrm{M}$ final concentration. The cells were washed twice with PBS containing proteinase inhibitors (1 mM PMSF, $1 \mathrm{mg} / \mathrm{ml}$ aprotinin, and $1 \mathrm{mg} / \mathrm{ml}$ pepstatin A). Nuclei were obtained using a nuclear purification kit (NUC-101; Sigma-Aldrich) supplemented with the same proteinase inhibitors according to the manufacturer's instructions. For each cell variant, 3 aliquots of $10^{6}$ nuclei were resuspended in SDS lysis buffer (1\% SDS, $10 \mathrm{mM}$ EDTA, $50 \mathrm{mM}$ Tris-HCl, $\mathrm{pH}$ 7.9) plus protease inhibitor cocktail for mammalian tissues (Sigma-Aldrich). The nuclei were sonicated to yield DNA fragments ranging from 0.1 to $1 \mathrm{~kb}$. Following centrifugation at $10,000 \times g$ for 10 minutes at $4^{\circ} \mathrm{C}$, one portion of the lysates was analyzed for DNA fragment size after reversing the cross-links and purification. The remaining supernatants were diluted 10 -fold with ChIP dilution buffer and incubated by rotation with $80 \mu \mathrm{l}$ of $50 \%$ salmon sperm DNA/protein A agarose beads for 90 minutes at $4^{\circ} \mathrm{C}$. The beads were removed by brief centrifugation at $4^{\circ} \mathrm{C}$, and $10 \mu \mathrm{l}$ of either rabbit preimmune serum or rabbit CBF-A antibody was added to the lysates and incubated by rotation overnight at $4^{\circ} \mathrm{C}$. The samples were subsequently incubated with $60 \mu \mathrm{l}$ of protein $\mathrm{A}$ agarose beads for 1 hour at $4^{\circ} \mathrm{C}$, and the beads were recovered by brief centrifugation and washed according to the manufacturer's protocol: once with low-salt $0.15 \mathrm{M} \mathrm{NaCl}$ buffer, once with high-salt $0.5 \mathrm{M} \mathrm{NaCl}$ buffer, and once with $0.25 \mathrm{M} \mathrm{LiCl}$ wash buffer. The pellets were washed once with $10 \mathrm{mM}$ Tris- $\mathrm{HCl}$ and $1 \mathrm{mM}$ EDTA, pH 8.0 (Tris-EDTA) and resuspended. The samples were split in 2, and the beads were collected by centrifugation; one portion was resuspended in SDS loading buffer, boiled for 10 minutes, and loaded on a ready-made 4\%-20\% SDS gradient gel (Bio-Rad) for Western blot analysis. The second portion for PCR analysis was resuspended in Tris-EDTA plus $0.2 \mathrm{M} \mathrm{NaCl}$ and incubated overnight at $65^{\circ} \mathrm{C}$ to reverse protein-DNA cross-links. This portion was used directly as a template for PCR analysis with primers producing an approximately 280-bp fragment encompassing the FTS- 1 site in both directions; custom FTS-1 primers (Invitrogen) were: 5'-GGTGGTAGATATTCTGCTCC-3' and 3'-TCTGCAACAACTCCTTGAGC-5'

EMSA. Nuclei were purified from cultured cells as described above and either frozen or extracted. Nuclear extracts were prepared in $400 \mathrm{mM}$ $\mathrm{KCl}$ buffered with $20 \mathrm{mM}$ HEPES pH 7.9 supplemented with a cocktail of proteinase inhibitors (Sigma-Aldrich). The protein extracts were brought down to $100 \mathrm{mM} \mathrm{KCl}$, and DNA binding activity was examined using the following oligonucleotide probes: FTS-1 (Invitrogen), regular: 5'CACTCACTACTTGATTGTGCCTGCT-3', mutated: 5'-CACTCACTACCCAGCTGTGCCTGCT-3'; YB-1 consensus site (Santa Cruz Biotechnology Inc.), regular: 5'-AGACCGTACGTGATTGGTTAATCTCTT-3', mutated: 5'-AGACCGTACGTGTAACCATAATCTCTT-3'; SRE (Santa Cruz Biotechnology Inc.), regular: 5'-GGATGTCCATATTAGGACATCT-3', mutated: 5'-GGATGTCCATATTATTACATCT-3'. EMSA was performed as described previously (60). Briefly, $10-15 \mu \mathrm{g}$ protein was incubated with $4 \times 10^{5} \mathrm{cpm}$ of [ ${ }^{32} \mathrm{P}$ ]ATP end-labeled oligonucleotides in $20 \mathrm{mM}$ HEPES pH 7.9 with $100 \mathrm{mM} \mathrm{KCl,} \mathrm{20 \%} \mathrm{glycerol,} \mathrm{and} 0.2 \mathrm{mM}$ EDTA. For competition analyses, protein was preincubated with unlabeled oligonucleotides or antibodies. FTS- 1 complexes were resolved by $5 \%$ PAGE using $0.5 \times$ Trisborate buffer $\mathrm{pH} 7.8$, vacuum dried, and subjected to PhosphorImager analysis (GE HealthCare). Two-dimensional EMSA/SDS-PAGE gels were run with a nonradiolabeled probe; the position of the complex in the first dimension was deduced from radiolabeled duplicates, and the gel piece was cut and inserted on top of the SDS gel. As a negative control, nuclear extract without DNA was run in parallel in the first dimension (EMSA), and the area corresponding to the complex was cut and run together with the real complex in the subsequent second dimension (SDS-PAGE). For mass spectrometry analyses, complexes of unlabeled FTS-1 were identified by reversible silver staining (SilverQuest; Invitrogen) and matched to radiolabeled samples run in parallel. In each experiment, stained complexes were cut from the gel and subjected to trypsinization before analysis.

DNA affinity chromatography. Regular and mutated 100-bp biotinylated tetramers of the 25-bp FTS-1 oligonucleotide were custom made by Invitrogen and attached to Dynabeads M-280 Streptavidin (DYNAL; Invitrogen). FTS-1-specific complexes were formed with fibroblast nuclear extracts at the conditions described for EMSA. The nuclear extracts were incubated first with the mutated tetramer, and the flow-through was used for a secondary incubation with the normal FTS-1 tetramer. The beads were washed 3 times with incubation buffer, and fractions were eluted with $0.5 \mathrm{M} \mathrm{KCl}$ followed by the same buffer plus $5 \mathrm{M}$ urea. The eluates were combined, dialyzed against $10 \mathrm{mM}$ Tris- $\mathrm{HCl} \mathrm{pH} \mathrm{7.5,} \mathrm{and}$ analyzed by EMSA for their ability to form the FTS- 1 complex. Positive fractions were trypsinized and subjected to tandem mass spectrometry for peptide identification.

Mass spectrometry analysis. Peptide mixtures were separated and analyzed using microcapillary reverse-phase HPLC (RP-HPLC) coupled to tandem 
mass spectrometry (25). Peptide mixtures were loaded onto a $75-\mu \mathrm{m}$ internal diameter RP-HPLC column (Poros R2; Perceptive Biosystems) equilibrated in $0.5 \%$ acetic acid and eluted using a linear gradient of $0 \%-40 \%$ acetonitrile over 60 minutes followed by $40 \%-60 \%$ over 10 minutes at a flow rate of $0.3 \mu \mathrm{l} / \mathrm{min}$. Eluting peptides were analyzed by electrospray ionization mass spectrometry using an ion trap mass spectrometer (Finnigan LCQ Deca; Thermo Scientific). All tandem spectra were searched against the NCBI nonredundant protein database (http://www.ncbi.nlm.nih.gov/ RefSeq/) using the SEQUEST algorithm $(25,61)$.

Generation of stable MCT/rCBF-A cell lines. A mammalian CBF-A/CBF-A expression vector, pSR-CBFA-N, was amplified using the Advantage PCR system (Clontech) with the following primers: the $5^{\prime}$ primer included an overhang with a unique BglII restriction site (ATTAGATCTGAGTAGCCGCTGCGGCCTGGCCGACCATGT) and the $3^{\prime}$ primer (ATTCTCGAGTCACTCGGCCGCTCCTGCTGCCTCTCAGTA) added a unique $X$ hoI site. Following restriction digestion, the sequence was subcloned into a pcDNA5/TO vector from the T-REx tetracycline inducible system (Invitrogen), producing the pcDNA5/TO/rCBF-A vector. MCT cells were transfected simultaneously with both the $\mathrm{pcDNA5} / \mathrm{TO} / \mathrm{rCBF}-\mathrm{A}$ vector and PcDNA6/TR regulatory vector of the T-REx system using SuperFect reagent (QIAGEN). Seven micrograms of TR plasmid and $3 \mu \mathrm{g}$ of rCBF-A plasmid were used to insure higher copy number of the regulatory factor. Following transfection, cells were switched to media with tetracyclinefree serum (Clontech). Twenty-four hours after transfection, recombinant cells were selected using $5 \mu \mathrm{g} / \mathrm{ml}$ blasticidin (Invitrogen). Once colonies formed, cells were tested for the presence of both vectors using the primers 5'-AGAGCTGCTTAATGAGGTCG-3' and 5'-GCATTATATGCACTCAGCGC-3' for the TR vector; and 5'-TGTCAGTGGAAGCAAGTGTG-3' and $5^{\prime}$-ACTAGAAGGCACAGTCGAGG-3' (vector BGH $3^{\prime}$-UTR specific) for rCBF-A. Cells were treated with $1 \mu \mathrm{g} / \mathrm{ml}$ doxycycline to induce rCBF-A and tested for changes in gene expression.

PCR analysis. All primers were custom made by Invitrogen: FSP1: sense, 5'-ATGGCAAGACCCTTGGAGGA-3', anti-sense, 5' -CATTGCACATCATGGCAATG-3'; GAPDH: sense, 5'-GCAGTGGCAAAGTGGAGATT-3', antisense, 5'-GCAGAAGGGGCGGAGATGAT-3'; rCBF-A: sense, 5'-TGTCAGTGGAAGCAAGTGTG-3'; anti-sense, 5'-ACTAGAAGGCACAGTCGAGG-3' (derived from BGH $3^{\prime}$-UTR of the vector). Reverse transcription PCR was performed using $5 \mu \mathrm{g}$ of total DNAse I-treated RNA with SuperScript reverse transcriptase (Invitrogen). Aliquots of cDNA, $2 \mu \mathrm{g}$ or $0.2 \mu \mathrm{g}$, were subjected to PCR for 40 cycles, with 10- $\mu$ l aliquots removed at 20, 25, 30, 35 , and 40 cycles. Fragments were separated in agarose gels and stained with ethidium bromide, and the images were analyzed using Scion Image (Scion Corp.). For qRT-PCR analysis, total RNA was collected at different time points, treated with DNAse I, and converted by reverse transcription. Primers/probes for CBF-A, FSP1, and GAPDH were from TaqMan Gene Expression Assays (Applied Biosystems). Gene quantification was performed on the Applied Biosystems 7900HT Fast Real-Time PCR System.
siRNA inbibition. The Silencer Pre-designed siRNA oligonucleotides (Ambion) targeted exons 2 and 3 or exon 4 of CBF-A/CBF-A. These exons are not subject to alternative splicing. Each siRNA was separately transfected into 3T3 fibroblasts using Lipofectamine 2000 (Invitrogen) following the manufacturer's instruction for transfection. Negative control siRNA (Ambion) was transfected in parallel for comparison. The levels of CBF-A and FSP1 expression were monitored at different time points after transfection by qRT-PCR using extracted total RNA and primers/probes as described above. The $\mathrm{Ct}$ values obtained were normalized against the corresponding $\mathrm{Ct}$ values of GAPDH. The results from 3 separate experiments were examined for statistical differences. siRNA3 was selected as a negative control due to its lack of effect on CBF-A expression.

Motility assay. Migration through a membrane in response to a serum gradient (Boyden chamber assay) was performed in 24-well culture plates with $8-\mu \mathrm{m}$ pore size inserts $(\mathrm{BD})$. Cells were grown for 5 days with or without doxycycline. Cells $\left(2 \times 10^{5}\right)$ in $0.1 \%$ BSA-containing medium were loaded onto the top of each membrane. The bottom wells contained 15\% FBS. When needed, doxycycline was added into both wells. The plates were incubated for 12 hours at $37^{\circ} \mathrm{C}$; membranes were removed and stained with Diff-Quik stain (IMEB). Cells were monitored in each field by a digital camera using a $\times 10$ objective lens (DM IRB; Leica). Six fields per membrane were counted in triplicate experiments.

Statistics. All values were expressed as mean \pm SEM. Mann-Whitney U tests were used to compare the mean of non-parametric groups. Values of $P$ less than 0.05 were considered statistically significant.

\section{Acknowledgments}

We thank Takeshi Miwa, Genome Information Research Center of Osaka University, for providing a mammalian CBF-A expression vector and Jonathan Dean, Imperial College of Science, London, for the anti-CBF-A antibody. We appreciate the valuable methodological help of Richard Caprioli and David Friedman at the Vanderbilt Mass Spectrometry facility. The authors are grateful to Linda Sealy (Vanderbilt) for critically reviewing an earlier version of the manuscript. E.G. Neilson was supported by NIH grants DK-46282, CA-68485, and DK-55926. A.J. Link was supported by NIH grants GM-64779, HL-68744, NS-43952, ES-11993, and CA098131. Y.N. Dimitrova was supported by NIH grants GM-62112 and GM-75156 (Chazin).

Received for publication June 29, 2006, and accepted in revised form December 5, 2006.

Address correspondence to: Eric G. Neilson, Department of Medicine, Vanderbilt University School of Medicine, D-3100 MCN, Nashville, Tennessee 37232, USA. Phone: (615) 322-3146; Fax: (615) 343-9391; E-mail: eric.neilson@vanderbilt.edu.
1. Kalluri, R., and Neilson, E.G. 2003. Epithelialmesenchymal transition and its implications for fibrosis. J. Clin. Invest. 112:1776-1784. doi:10.1172/ JCI200320530.

2. Thiery, J.P., and Sleeman, J.P. 2006. Complex networks orchestrate epithelial-mesenchymal transitions. Nat. Rev. Mol. Cell Biol. 7:131-142.

3. Strutz, F., et al. 1995. Identification and characterization of a fibroblast marker: FSP1. J. Cell Biol. 130:393-405.

4. Iwano, M., et al. 2002. Evidence that fibroblasts derive from epithelium during tissue fibrosis. Invest. 110:341-350. doi:10.1172/JCI200215518.

5. Vongwiwatana, A., Tasanarong, A., Rayner, D.C., Melk, A., and Halloran, P.F. 2005. Epithelial to mesenchymal transition during late deterioration of human kidney transplants: the role of tubular cells in fibrogenesis. Am. J. Transplant. 5:1367-1374.

6. Okada, H., Danoff, T.M., Kalluri, R., and Neilson, E.G. 1997. Early role of Fsp1 in epithelial-mesenchymal transformation. Am. J. Physiol. 273:F563-F574.

7. Kawakita, T., et al. 2005. Intrastromal invasion by limbal epithelial cells is mediated by epithelialmesenchymal transition activated by air exposure. Am. J. Pathol. 167:381-393.

8. Nishitani, Y., et al. 2005. Fibroblast-specific protein 1 is a specific prognostic marker for renal survival in patients with IgAN. Kidney Int. 68:1078-1085.

9. Lawson, W.E., et al. 2005. Characterization of fibroblast-specific protein 1 in pulmonary fibrosis. $\mathrm{Am}$. J. Respir. Crit. Care Med. 171:899-907.
10. Jenkinson, S.R., Barraclough, R., West, C.R., and Rudland, P.S. 2004. S100A4 regulates cell motility and invasion in an in vitro model for breast cancer metastasis. Br. J. Cancer. 90:253-262.

11. Yang, J., et al. 2004. Twist, a master regulator of morphogenesis, plays an essential role in tumor metastasis. Cell. 117:927-939.

12. Sherbet, G.V., and Lakshmi, M.S. 1998. S100A4 (MTS1) calcium binding protein in cancer growth, invasion and metastasis. Anticancer Res. 18:2415-2421.

13. Xue, C., Plieth, D., Venkov, C., Xu, C., and Neilson, E.G. 2003. The gatekeeper effect of epithelialmesenchymal transition regulates the frequency of breast cancer metastasis. Cancer Res. 63:3386-3394.

14. Grum-Schwensen, B., et al. 2005. Suppression of 
tumor development and metastasis formation in mice lacking the S100A4(mts1) gene. Cancer Res. 65:3772-3780.

15. Cho, Y.G., et al. 2005. Overexpression of S100A4 is closely associated with progression of colorectal cancer. World J. Gastroenterol. 11:4852-4856.

16. Gupta, P.B., et al. 2005. The melanocyte differentiation program predisposes to metastasis after neoplastic transformation. Nat. Genet. 37:1047-1054.

17. Moriyama-Kita, M., et al. 2005. S100A4 regulates E-cadherin expression in oral squamous cell carcinoma. Cancer Lett. 230:211-218.

18. Shook, D., and Keller, R. 2003. Mechanisms, mechanics and function of epithelial-mesenchymal transitions in early development. Mech. Dev. 120:1351-1383.

19. Kang, Y., and Massague, J. 2004. Epithelialmesenchymal transitions; twist in development and metastasis. Cell. 118:277-279.

20. Nieto, M.A. 2002. The snail superfamily of zincfinger transcription factors. Nat. Rev. Mol. Cell Biol. 3:155-166.

21. Thuault, S., et al. 2006. Transforming growth factor-beta employs HMGA2 to elicit epithelialmesenchymal transition. J. Cell Biol. 174:175-183.

22. Macias, D., Perez-Pomares, J.M., Garcia-Garrido, L., Carmona, R., and Munoz-Chapuli, R. 1998. Immunoreactivity of the ets- 1 transcription factor correlates with areas of epithelial-mesenchymal transition in the developing avian heart. Anat. Embryol. 198:307-315.

23. Lie-Venema, H., et al. 2003. Ets-1 and Ets-2 transcription factors are essential for normal coronary and myocardial development in chicken embryos. Circ. Res. 92:749-756.

24. Okada, H., et al. 1998. Identification of a novel cisacting element for fibroblast-specific transcription of the FSP1 gene. Am. J. Physiol. 275:F306-F314.

25. Link, A.J., et al. 1999. Direct analysis of protein complexes using mass spectrometry. Nat. Biotechnol. 17:676-682.

26. Kamada, S., and Miwa, T. 1992. A protein binding to CArG box motifs and to single-stranded DNA functions as a transcriptional repressor. Gene. 119:229-236.

27. Friedman, J.R., et al. 1996. KAP-1, a novel corepressor for the highly conserved KRAB repression domain. Genes Dev. 10:2067-2078.

28. Kultz, D., Madhany, S., and Burg, M.B. 1998. Hyperosmolality causes growth arrest of murine kidney cells. Induction of GADD45 and GADD153 by osmosensing via stress-activated protein kinase 2. J. Biol. Chem. 273:13645-13651.

29. Cohn, M.A., et al. 2001. Characterization of Sp1, $\mathrm{AP}-1, \mathrm{CBF}$ and $\mathrm{KRC}$ binding sites and minisatellite DNA as functional elements of the metastasisassociated mts1/S100A4 gene intronic enhancer. Nucleic Acids Res. 29:3335-3346.

30. Xiao, Z.S., Thomas, R., Hinson, T.K., and Quarles, L.D. 1998. Genomic structure and isoform expression of the mouse, rat and human Cbfa1/Osf2 transcription factor. Gene. 214:187-197.

31. de Bruijn, M.F., and Speck, N.A. 2004. Core-binding factors in hematopoiesis and immune func- tion. Oncogene. 23:4238-4248.

32. Liang, S.G., and Maity, S.N. 1998. Pathway of complex formation between DNA and three subunits of CBF/NF-Y. Photocross-linking analysis of DNAprotein interaction and characterization of equilibrium steps of subunit interaction and dna binding. J. Biol. Chem. 273:31590-31598.

33. Song, W.J., et al. 1999. Haploinsufficiency of CBFA2 causes familial thrombocytopenia with propensity to develop acute myelogenous leukaemia. Nat. Genet. 23:166-175.

34. Gao, C., et al. 2004. S-nitrosylation of heterogeneous nuclear ribonucleoprotein A/B regulates osteopontin transcription in endotoxin-stimulated murine macrophages. J. Biol. Chem. 279:11236-11243.

35. Mikheev, A.M., Mikheev, S.A., Zhang, Y., Aebersold, $\mathrm{R}$, and Zarbl, H. 2000. CArG binding factor A(CBF-A) is involved in transcriptional regulation of the rat Ha-ras promoter. Nucleic Acids Res. 28:3762-3770.

36. Leverrier, S., et al. 2000. Purification and cloning of type A/B hnRNP proteins involved in transcriptional activation from the Rat spi 2 gene GAGA box. Biol. Chem. 381:1031-1040.

37. Bemark, M., Olsson, H., Heinegard, D., and Leanderson, T. 1998. Purification and characterization of a protein binding to the SP6 kappa promoter. A potential role for CArG-box binding factor-A in kappa transcription. J. Biol. Chem. 273:18881-18890.

38. Weisman-Shomer, P., Cohen, E., and Fry, M. 2002. Distinct domains in the CArG-box binding factor A destabilize tetraplex forms of the fragile $\mathrm{X}$ expanded sequence d(CGG)n. Nucleic Acids Res. 30:3672-3681.

39. Hou, V.C., et al. 2002. Decrease in hnRNP A/B expression during erythropoiesis mediates a premRNA splicing switch. EMBOJ. 21:6195-6204.

40. Dean, J.L., et al. 2002. Identification of a novel AUrich-element-binding protein which is related to AUF1. Biochem. J. 366:709-719.

41. Percipalle, P., et al. 2002. Nuclear actin is associated with a specific subset of hnRNP A/B-type proteins. Nucleic Acids Res. 30:1725-1734.

42. Umar, A., Luider, T.M., Berrevoets, C.A., Grootegoed, J.A., and Brinkmann, A.O. 2003. Proteomic analysis of androgen-regulated protein expression in a mouse fetal vas deferens cell line. Endocrinology. 144:1147-1154.

43. Mikheev, A.M., et al. 2004. Frequent activation of CArG binding factor-A expression and binding in $\mathrm{N}$-methyl-N-nitrosourea-induced rat mammary carcinomas. Breast Cancer Res. Treat. 88:95-102.

44. Ramaswamy, S., Ross, K.N., Lander, E.S., and Golub, T.R. 2003. A molecular signature of metastasis in primary solid tumors. Nat. Genet. 33:49-54.

45. Jeffery, C.J. 2003. Moonlighting proteins: old proteins learning new tricks. Trends Genet. 19:415-417.

46. Ryan, R.F., et al. 1999. KAP-1 corepressor protein interacts and colocalizes with heterochromatic and euchromatic HP1 proteins: a potential role for Kruppel-associated box-zinc finger proteins in heterochromatin-mediated gene silencing. Mol. Cell. Biol. 19:4366-4378.

47. Lechner, M.S., Schultz, D.C., Negorev, D., Maul,
G.G., and Rauscher, F.J., III. 2005. The mammalian heterochromatin protein 1 binds diverse nuclear proteins through a common motif that targets the chromoshadow domain. Biochem. Biophys. Res. Commun. 331:929-937.

48. Schultz, D.C., Ayyanathan, K., Negorev, D., Maul, G.G., and Rauscher, F.J., III. 2002. SETDB1: a novel KAP-1-associated histone $\mathrm{H} 3$, lysine 9-specific methyltransferase that contributes to HP1-mediated silencing of euchromatic genes by KRAB zincfinger proteins. Genes Dev. 16:919-932.

49. Ayyanathan, K., et al. 2003. Regulated recruitment of HP1 to a euchromatic gene induces mitotically heritable, epigenetic gene silencing: a mammalian cell culture model of gene variegation. Genes Dev. 17:1855-1869.

50. Anderson, M., et al. 2002. A new family of cyclophilins with an RNA recognition motif that interact with members of the trx/MLL protein family in Drosophila and human cells. Dev. Genes Evol. 212:107-113

51. Fair, K., et al. 2001. Protein interactions of the MLL PHD fingers modulate MLL target gene regulation in human cells. Mol. Cell. Biol. 21:3589-3597.

52. Aranburu, A., Bennett, M., and Leanderson, T. 2006. The kappa promoter penta-decamer binding protein CBF-A interacts specifically with nucleophosmin in the nucleus only. Mol. Immunol. 43:690-701.

53. Cano, A., et al. 2000. The transcription factor snail controls epithelial-mesenchymal transitions by repressing E-cadherin expression. Nat. Cell Biol. 2:76-83.

54. Thiery, J.P. 2002. Epithelial-mesenchymal transitions in tumour progression. Nat. Rev. Cancer. 2:442-454.

55. Tanaka, H., et al. 2005. siRNA gelsolin knockdown induces epithelial-mesenchymal transition with a cadherin switch in human mammary epithelial cells. Int. J. Cancer. 118:1680-1691.

56. Gilles, C., Polette, M., Birembaut, P., Brunner, N., and Thompson, E.W. 1997. Expression of c-ets-1 mRNA is associated with an invasive, EMT-derived phenotype in breast carcinoma cell lines. Clin. Exp. Metastasis. 15:519-526.

57. Savagner, P. 2001. Leaving the neighborhood: molecular mechanisms involved during epithelialmesenchymal transition. Bioessays. 23:912-923.

58. Haverty, T.P., et al. 1988. Characterization of a renal tubular epithelial cell line which secretes the autologous target antigen of autoimmune experimental interstitial nephritis. J. Cell Biol. 107:1359-1368.

59. Bhowmick, N.A., et al. 2004. TGF-beta signaling in fibroblasts modulates the oncogenic potential of adjacent epithelia. Science. 303:848-851.

60. Venkov, C.D., Rankin, A.B., and Vaughan, D.E. 1996. Identification of authentic estrogen receptor in cultured endothelial cells. A potential mechanism for steroid hormone regulation of endothelial function. Circulation. 94:727-733.

61. Eng, J., McCormack, A.L., and Yates, J.R., III. 1994. An approach to correlate tandem mass spectral data of peptides with amino acid sequences in a protein database. J. Amer. Soc. Mass Spectrom. 5:976-989. 